\title{
The Status of Teacher's Questions and Students' Responses: The Case of an EFL Class
}

\author{
Arman Toni \\ Science and Research Branch, Islamic A zad University, Tehran, Iran \\ Farzad Parse \\ Ghasr-e-Shirin Branch, Islamic A zad University, Iran
}

\begin{abstract}
Whereas a lot of classroom research conducted in English classes have studied the role of classroom interaction, a considerable number of research has been concerned with the linguistic aspects of classroom interaction, many of which dealt with the type of questions asked in the EFL classes. Previously it was demonstrated that teachers make adjustments in their questioning techniques when communicating with their students. In the same line of inquiry, the present study tried to find out what techniques of questioning teachers use to engage their students in classroom interaction. The present paper, which is based on a case study, investigates classroom interactions in terms of questions being asked by the teacher. To this end, Bloom's (1956) taxonomy was selected as the framework of analysis. A class of six adolescent students, who were both male and female, participated in the study. For the purpose of this study, three 45-minute sessions of classroom interactions between the teacher and the participant were randomly tape recorded. After analyzing the obtained data, it was found that the inference question, among different question types, was the most frequently posed question in the target classroom with $27 \%$ of occurrence. Based on the obtained results, it is claimed that the study is a contribution to the characterization of teacher-student interactions. Moreover, some suggestions for further research are presented.
\end{abstract}

Index Terms - teacher questioning, classroom interaction, inference questions

\section{INTRODUCTION}

There is a large body of literature available on observational studies completed in both ESL and EFL classes. Whereas a lot of classroom research conducted in English classes have studied the role of classroom interaction, a considerable number of research has been concerned with the linguistic aspects of interaction and second language acquisition (SLA). In this respect, there have been many studies on in-class teacher questions many of which have dealt with the type of question asked in EFL classes. For the purpose of this study, a review of related literature seems noteworthy. To begin with, there is an overview of theories on the role of questions in SLA, as well as studies of questions in EFL classes. It is believed that a review of studies sheds light on the ways in which teacher questions vary depending on the class type, and is a necessary step toward ascertaining possible causes for different questions and response behaviors in EFL classes.

\section{RE VIEW OF RELATED LITERATURE}

As noted by Gall (1970), questions play a pivotal role in teaching. He calls upon researchers to identify the criteria of effective questions and determine how questions can help students achieve educational objectives. The differences in the way in which teachers use questions have been documented. Barnes (1990) states that teachers use questions to channel students into specific modes of participation. He discusses, for instance, the use of closed and open -ended questions. Closed questions are expected to elicit a closed set of responses (e.g. "Where were you born?"). In contrast, open-ended questions leave open the nature and length of the response (e.g. "What did you do on your trip?"). According to Barnes, the use of these two question types influences students' participation. By being asked closed questions, the student is normally expected to reproduce information or reasoning. On the other hand, open -ended questions help the student to explore the subject matter and encourage him/her to think aloud. Whereas closed questions encourage passive participation, open-ended questions cause students to take a more active role in the classroom.

Chaudron (1988) also describes the role of teachers' questions as an important aid to get students' attention, and enhancing learners' verbal replies and assessing their improvement, but states that questions alone may not always promote a great amount of interaction. He reports on many characteristics of teachers' questions. He maintains, for example, that teachers ask proportionately more display than referential questions. He also reports that EFL teachers have a tendency to repeat or rephrase questions more often than teachers in native speaker classes. Further, he mentions that comprehension question checks, confirmations checks and clarification requests occur more frequently in EFL classes. He suggests ".. that the adjustments in teacher speech to nonnative-speaking learners serve the temporary purpose of maintaining communication-clarifying in formation and eliciting learners' responses...” (p. 55). 
Brock (1984, cited in Godfrey, 2001, p. 20) notes that teachers in EFL classes pose far fewer referential questions than native speakers do in informal conversation. Her study looks at the effect of higher frequencies of referentia 1 questions in adult classes. She claims that refe rential questions are on a higher cognitive level than display questions. In her study, two teachers were trained in the use of referential questions, and assigned to teach two classes for adults. These two teachers increased the number of referential questions used significantly as compared to two control group teachers. This resulted in learner responses that were on average twice as long as and more syntactically complex than their responses to display questions. In addition, the students used a far greater number of logical connectors. She suggests that the increased use of referential questions may give students opportunities for practice and output that may contribute to their acquisition process.

White and Lightbown (1984) assert that teachers tend to dominate the class, control the topics and speaking turns of the conversations, and ask most of the questions. In addition, they ask a lot of display questions and help students respond to them. Moreover, students repeat and rephrase questions if they do not get an immediate response to the initial question. They argue that the result of these series of repetitions is an extended sequence of interactions during which the teacher and the student together create the students' answer, rather than students producing the question unaided. White and Lightbown's observations are based to a large extent on high school EFL classes in Canada, a group that is, more or less, similar to the class type that participated in the current study.

All of the above studies suggest that teachers in general modify their questioning behaviors to meet their instructional goals. Based on the results from these studies, there is now evidence that teachers modify their questioning techn iques as a result of perceptions of their students' comprehension and general language proficiency. With reference to the aim of the present study regarding questioning techniques, the results of these investigations provide valuable background information.

Typological Frameworks

Questions can be used for different aims in education. They can be asked for the purpose of directing the students to the target, providing them to thin $\mathrm{k}$ at high level and effectively by directing them to questioning, determining the efficiency of education, increasing students' attendance, improving students' listening skills and increasing tolerance and respect. It can be benefited from questioning for the purpose of providing effective classroom management and decreasing classroom problems.

Bond (2007) presents some suggestions about questioning by paying attention to questioning strategies to decrease classroom management problems. These are:

1. Prepare a number of questions when writing the lesson plan;

2. Form prospects of the learners' probable reactions before commencing questioning;

3. Ask questions from a variety of students;

4. Signal students before questioning;

5. Question at the level of students' proficiency;

6. Ask questions that elicit accurate responses;

7. Offer students adequate wait time after asking a question;

8. Vary and change the way students answer the questions;

9. Ask questions from different learners;

10. Respond to each of the replies and correct the errors;

11. Ask follow-up questions;

12. Encourage and motivate learners to ask questions.

There are different question forms in teaching-learning process. Grouping questions differs according to different authors. In one of the earliest taxonomies, Bloom (1956, cited in Brown, 2007, p. 172) categorizes questions into the following groups:

1. Knowledge: the recalling of formerly-learned material (e.g. What is the special name of this triangle?)

2. Comprehension: the ability to understand the meaning (e.g. Explain how you got that answer.)

3. Application: the ability to use learned material such as rules, methods, concepts, principles, laws and theories in new and concrete situations (e.g. Give me an example of a situation that you may have this experience.)

4. Inference: the ability to form conclusions that are not directly stated in instructional materials. (e.g. How do you feel about it?)

5. Analysis: the ability to breakdown material into its elements so that its organizational structure may be understood .This may involve the classification of parts, exploration of the association between them, and identification of organizational princip les (e.g. Why did that work in this case?)

6. Synthesis: the ability to collect different parts and put them together to create a new whole. Synthesis encourages learners to form something new and rely on innovative and creative thin king. (e.g. What would happen if you called him?)

7. Evaluation: the ability to assess the value of materials, the explanation to problems or the details about particular cultures (What do you think?)

Barnes (1976, cited in Ellis, 2008, p. 797), for instance, distinguished four types of questions: (1) factual questions (e.g. What?), (2) reasoning questions (e.g. How?, Why?), (3) open questions, which require no reasoning, (4) social 
questions, that are questions that affect learner behavior through controlling or appealing. Barnes also made a distinction between closed questions (i.e. questions that are structured with just one acceptable answer in mind) and open questions (i.e. questions that permit a number of different acceptable answers).

By handling the questions with a cross-disciplinary review, Kearsley (1976, cited in Shomoossi, 1997) conducted questions in verbal discourse and made the following taxonomy of questions' functions:

1. Echoic: those which ask for the repetition or reiteration of a statement or verification whether an utterance has been understood as intended (e.g. Excuse me?! Pardon me?! What?!).

2. Ep istemic: those which projects to acquire information:

(a) Referential: intended to provide contextual information about situations, occasions, activities, purposes, relations or possessions (Wh-questions, for example).

(b) Evaluative: asked to check the addressee's understanding of the answer (sometimes called display, test or known information questions)

3. Expressive: conveying attitudinal information to the addressee (e.g. Are you coming or aren't you?)

4. Social control: used to maintain power by preserving control of the dialog.

5. Attentional: allows the questioner to govern the direction of the dialog (meta-message is "listen to me" or "think about this").

6. Verbosity: asked only for the sake of politeness or to sustain conversation (e.g. cocktail party questions).

Long and Sato (1984, cited in Ellis, 2008, p. 797) modified Kearsley's taxonomy to account for the different types of teachers' questions they observed in ESL classes. The key distinction was between echoic questions, which ask for the reiteration of an utterance or verification that it has been understood as intended, and epistemic questions, which serve the purpose of acquiring information. Long and Sato also termed Kearsley's evaluative epistemic questions as "display questions". By and large, this distinction is similar but not identical to the open/closed distinction of Barnes.

In his research, Bishop (1991) introduces what the questions are used for in classroom discussions and groups question forms as open-ended, information-seeking, diagnostic, challenge/testing, priority and sequence, action, prediction, hypothetical, extension and generalization ones.

Martin (2003) groups the question forms in three as genuine, test and provoking ones, and indicated that $61 \%$ of the teachers ask test questions (How many sides in a triangle? How can we simplify this fraction?), $25 \%$ of them ask genuine questions (How many different triangles did you find? Which measurement did you use?), and $14 \%$ of them ask provoking questions (Why is that? How could you achieve that?).

In general, according to Ellis (2008), "studies of teachers' questions in the L2 classroom have focused on the frequency of the different types of questions, wait-time (the length of the time the teacher is prepared to wait for an answer), the nature of the learners' output when answering questions, the effect of the learners' level of proficiency on questioning, the possibility of training teachers to ask more communicative questions, and the variation evident in teachers' questioning strategies" (p. 798). In much of the research, it has been assumed that L2 learning will be improved provided that the questions lead to active student participation and negotiation of meaning.

\section{ST ATEMENT OF THE PROBLEM}

As can be seen, numerous studies of teacher questions in English classes have been carried out, mostly of which demonstrate that teachers make adjustments in their questioning techniques when communicating with their students. In these studies, the focus is frequently on the type of questions being asked.

In the same line of inquiry, this study aimed to explore the is sue from a particular perspective. More specifically, the present study tried to find out what techniques of questioning teachers use to get their students involved in classroom interactions as well as to help construct their knowledge of language. To this end, Bloom's (1956) taxonomy was selected as the framework of analysis, since it was believed that this taxonomy would better aid to interpret and analy ze the types of questions having been asked in the classroom.

For the purpose of this study, it was also believed that case studies due to their better control and manageability would provide the researcher with an appropriate tool to analytically probe into the teacher-question-student-response phenomenon. Therefore, the current paper is a case study which intends to investigate classroom interactions in terms of questions being asked by the teacher.

\section{MEthodOLOGY}

\section{A. Participants}

This study was conducted in a language institute in Tehran. The class comprised of six adolescent students, aged between thirteen and nineteen. The class members were both male and female. Almost all of the class members had started studying English about one year prior to the date of the study, and at the time the study was being conducted they were considered as lower-intermediate EFL learners at the beginning of the sixth semester. The learners are students of high- and junior high school. They were passing a course of English communication based on Top Notch 2, Volume A. 
With a first insight into the condition of class members, it was found that the researcher would face a homogenous class. According to a person-to-person dialog between the researcher and each of the participants, all of the subjects seem to have integrative intrinsic motivation to learn English, since they claim they like the language and the culture of people very much. Except one the participants who was already a university student, the rest have this plan to get into university in the near future and two of them were actually preparing themselves to sit the university examinations that year. Class members seemed to be outgoing, easy going and more or less smart. During the study, they creatively and actively participated in class discussions and exercises. In the course of the study, it was found out that two of the class members, both female, seemed to be more talented in learning new things. A mong class students, only one male was found to be introvert so that he needed to be pushed to engage in class discussions, however, from the vie wpoint of the researcher his knowledge of language was regarded as satisfactory and fit to his level.

The major problem with most of the students is their listening, and almost all of them claimed that they were not satisfied with their listening skill. However, they would all respect the class regulations and bring the transcriptions of the listening of their books with themselves every session. Unfortunately, during the study, there was not a chance of tapping into students' knowledge of writing. However, regarding students' reading ability, it can be said that the subjects were keen in comprehending new te xts, of diffe rent topics, at their level.

Finally, it should be noted that except one of the students who was a bilingual Persian-Turkish learner, the other class members were monolingual and their mother tongue is Persian.

\section{B. Design}

This study favors the expost facto design in that there is no cause-effect relationship. There is also no treatment. The researcher has no control over the selection and the manipulation of the variables in what has already occurred to the subjects of the study. Moreover, the design of the present study can be considered as descriptive, since the researcher presents descriptions concerning naturally occurring phenomena connected with language development and processing, and there is no major statistical operation used in the study.

\section{Procedure}

As was mentioned earlier, in the present study the data was collected from a group of adolescent English learners studying in the lower-intermediate level in language institute. The subjects were studying Top Notch, volume 2; and besides the main course book, all of them participated in a 2-hour movie class one session a week. As for the curiosity of the researcher-not for the purpose of the study-every single individual was informally intervie wed during the course of study, in order to grasp the idea of how homogenous the class was regarding the students' background, age, major, social interaction, social behavior, degree of extroversion, and other affective variables.

In order to collect data necessary for the interpretation of teacher-questions-student-responses, it was decided that three sessions of classroom interactions between the teacher and the participant be randomly tape recorded. The recording time of each session was 45 minutes. During the recording period, participants were not aware that their interactions with the teacher as well as with each other was being recorded. The researcher who was also the teacher of the class did his best not to alter or modify his instruction for the purpose of the study so that classroom interactions be as natural as possible. Therefore, it was expected that the study would have almost no impact on classroom interaction, one part of which was teacher questioning and students' responses.

In order for the participants to attend with preparation and to answer the questions appropriately, they were provided with sufficient time to think about the questions being asked. After the observation was over, the tape recordings were transcribed for the purpose of subsequent analysis.

\section{Data Analysis and Discussion}

In accordance with the pre-determined purpose of the study, the data related to the classroom interaction between the teacher and the students was first gathered by means of tape recording and then transcribed for further analysis. The content of the transcription acquired from the tape-recorded data was analyzed by using a technique called content analysis (Silverman; 1993). The steps of the activity related to this content analys is are as follows:

- In the first step, the recorded data was examined and the questions were transcribed one by one.

- The questions were classified and their frequency was examined in terms of the subject as well as the class of the questions.

- The analysis of the results was presented as of percentage and frequency by tabulating the data in direction of the categories determined.

Next, a table was designed to record the results from the content analysis of the transcribed data. Based on Bloom's taxonomy of teachers' questions, six different categories of teachers' questions were identified and the frequency of occurrence of every question type was entered into the table. Table I gives an overview of the results. 
TABLE I

FREQUENCY AND PERCENTAGE OF THE OCCURRENCE OFQUESTIONS

\begin{tabular}{|l|l|l|}
\hline Question Type & Frequency of Occurrence & Percentage (\%) \\
\hline Knowledge & 36 & 11 \\
\hline Comprehension & 72 & 22 \\
\hline Application & 52 & 16 \\
\hline Inference & 87 & 27 \\
\hline Analysis & 24 & 8 \\
\hline Synthesis & 8 & 3 \\
\hline Evaluation & 43 & 13 \\
\hline Overall & 322 & 100 \\
\hline
\end{tabular}

As can be seen from the table, a total number of 322 questions were raised by the teacher in this study. Among questions, inference questions were found to be the most frequently occurring question types posed in the target classroom, by the frequency of 87 questions and total percentage of $27 \%$. Co mp rehension question types ranked second by the occurrence of 72 in the total number of 322, i.e. 22 per cent of frequency. Application, evaluation, knowledge and analysis questions ranked third, fourth, fifth and sixth respectively. Synthesis questions were found to be the least posed questions in our study of classroom teacher questioning.

Based on the results from the study, one might say that the teacher in this study used inference questions far more than other types of questions. According to Bloom (1956, cited in Brown, 2007), inference questions are the ones that are posed to elicit conclusions about matters which were not directly stated in instructional materials (p. 172). Inference questions essentially strive to illustrate logical and rational proficiencies of learners, that is, their competence. In so doing, they address "such questions as what types of knowledge transformations occur in different learn ing processes; what is the validity of knowledge obtained through different types of learning, how prior knowledge is used; what knowledge can be derived from the given input and the prior knowledge; how learning goals and their structure influence learning processes; how learning processes can be classified and evaluated from the vie wpoint of their logical capabilities, etc" (Michalski, 1993, p. 3).

The rationale behind inference questions stresses the role of learner's background knowledge, and the significance of learning goals. Question words such as "how" and "why" are commonly used to make inference questions. Examples of inference questions are "What did he mean by saying ...?" and "What conclusions can you draw from ...?". It can be said that inference questions are a great help in guiding learners toward brainstorming, thinking about subject matters and drawing conclusions.

\section{CONCLUSION AND IMPLICATION}

Questioning is an essential component of teaching. Tsui, Marton, Mok and Ng (2004) assert that questions can draw learners' attention to the critical aspects of the object of learning, and open up the space for more investigation on the part of learners. As for this study, it was intended to investigate how, in a given setting, teacher questioning is associated with instruction and how it directs later student responses. In so doing, Bloom's typological framework was developed for the purpose of describing and analyzing classroom discourse, with a focus on question-response interactions. The framework was used to analyze the ways in which the teacher had used questions to structure and lead classroom interactions. It is believed, now, that the representation of teacher questioning in the classroom contributes to an understanding of how questions can inspire students to respond as part of a teaching sequence (Chin, 2006). The analysis of classroom discourse reveals that teacher's questions are not only evaluative but also supportive in that it seems that questions provoke deeper thinking in the students. Moreover, it engages students in more cognitively active roles. As Chin (2006, p. 1336) puts it, teachers' questions stimulate students to "formulate hypotheses, predict outcomes, brainstorm ideas, generate explanations, make inferences and conclusions, as well as to self-evaluate and reflect on their own thinking." It can be hypothesized that by questioning, the teacher provides not only conceptual but also linguistic scaffolding (ibid).

Teachers' questions that elicit information about students' understanding can also be considered as an essential tool for formative assessment. Furthermore, as Black and Harrison (2001) point out, since the quality of teachers' questions can affect the degree to which the questions do or do not extend students' thinking and prolong their ideas, both the actual content of the questions and the ways of following up on the responses, i.e. feedback, become remarkable. Thus, an implication of the present study would be that teachers ought to think about how questions can be constructed and implemented to develop students' learning.

This study also contributes to the description and characterization of teacher-student discourse. By the aid of an analysis of the relationship between the aspects of teacher-student interactions, some facilitating strategies related to teacher questioning can be identified. As a case in point, students can be developed mentally through thoughtful teacher-led but not teacher-centered discourse. As leaders of classroom interactions in shaping students' learning, teachers ought to position themselves as facilitators of talk for thinking. It is worth mentioning that, apparently, students ask fewer questions than teachers in class and that students do not ask other students almost any questions. Therefore, it is suggested that teachers provide students with opportunities to exchange information and experience about making the lesson more active. In so doing, teachers are recommended to increase student-teacher and student-student interaction. 


\section{REFERENCES}

[1] Barnes, D. (1990). Language in the secondary classroom. In D. Barnes, J. Britton \& M. Torbe (Eds.), Language, the learner and the school (4 ${ }^{\text {th }}$ ed.), (pp. 9-88). Portsmouth: Cook Publishers.

[2] Bishop, P. E. (1991). Asking the Right Questions: Teacher Talk and Critical Thinking. Annual Conference of the Community College Humanities Association. San Fran cisco.

[3] Black, P., \& Harrison, C. (2001). Feedback in questioning and marking: The science teacher's role in formative assessment. School Science Review, 82(301), 55-61.

[4] Bond, N. (2007). Questioning strategies that minimize classroom management problems. Kapa Delta Pi Record.

[5] Brown, H. D. (2007). Teaching by principles: An interactive approach to language pedagogy. NY: Pearson Education.

[6] Chaudron, C. (1988). Second lan guage classrooms: Research on teaching and learning. Cambridge: CUP.

[7] Chin, C. (2006). Classroom Interaction in Science: Teacher questioning and feedback to students' responses. International Journal of Science Education, 28(11), 1315-1346.

[8] Ellis, R. (2008). The study of second language acquisition $\left(2^{\text {nd }}\right.$ ed.). Oxford: OUP.

[9] Gall, M. D. (1970). The use questions in teaching. Review of educational research, 40, 707-721.

[10] Godfrey, K. A. (2001). Teacher questioning techniques, student responses and critical thinking. Master's Thesis. Retrieved January, 2012, from http://www.eric.ed.gov/PDFS/ED459609

[11] Martin, N. (2003). Questioning styles. Mathematics Teaching, 184, 18-19.

[12] Michalski, R. S. (1993). The inferential theory of learning: Developing foundations for multistrategy learning. In R. S. Michalski \& G. Tecuci (Eds.), Machine Learning: A Multistrategy Approach. Morgan Kaufman Publishers. Retrieved January, 2012, from http://citeseer x.ist.psu.edu/viewdoc/download?doi=10.1.1.64.909\&rep=rep $1 \&$ type=pdf.

[13] Shomoossi, N. (1997). The effect of teacher's questioning behavior on EFL classroom interaction: A classroom-based research. Master's thesis: University of Allameh Tabatabaee, Deparment of English, Faculty of Literrature and Foreign Lan guages.

[14] Silverman, D. (1993). Interpreting qualitative data: Methods for analyzing talk, text and interaction. London: Sage Publication.

[15] Tsui, A. B. M., Marton, F., Mok, I. A. C., \& Ng, D. F. P. (2004). Questions and the space of learning. In F. Marton \& A. B. M. Tsui (Eds.), Classroom discourse and the space of learning (pp. 113-137). Mahwah, NJ: Lawrence Erlbaum.

[16] White, J., \& Lightbown, P. (1984). Asking and answering in language classes. The Canadian Modern Language Review, 40, $228-244$.

Arman Toni is currently a Ph.D. candidate majoring in TEFL at IAU, Science and Research Branch, Tehran, Iran. He received his M.A. in TEFL from Ilam State University and is currently a visiting instructor at MSRT and IAU, Iran.

Farzad Parse holds an M.A. in TEFL from Ilam State University, Iran. He is now a faculty member at IAU, Ghasr-e-Shirin Branch, Iran, where he has been teaching General English and EAP courses for the past four years. He has presented a number of papers in national conferences His main areas of interest are teacher feedback, error analysis and the implementation of translation techniques in lan guage teaching. 